\title{
Inspiration and Optimizing Countermeasures of Foreign Experience in China's Home-based Care
}

\author{
Feng Pan \\ School of Literature, Law and Economics \\ Wuhan University of Science and Technology \\ Wuhan, China 430065
}

\author{
Yang Wang \\ School of Literature, Law and Economics \\ Wuhan University of Science and Technology \\ Wuhan, China 430065
}

\begin{abstract}
Exploring and improving the approaches of China's endowment models are very necessary for population aging has been the trend of social development coupled with China's special conditions of old before getting rich and more severe situation of supporting for the elders. The model of community home care service becomes a mainstream from an international perspective. This paper summarizes the significance of the community home care service, discusses the currentsituation of the development of the old-age service model in China's community, puts forward the problems and causes, and introduces the development model and characteristics of the United States and Japan in detail. Accordingly, drawing on the good concepts of foreign community service model, it puts forward the proposals to improve and innovate Chinese community home care service models.
\end{abstract}

Keywords-community pension service; home-based care; foreign

\section{INTRODUCTION}

At present, the number of elderly people aged 80 and above has reached 20.99 million, accounting for $1.57 \%$ of the total population of the country (the data sources from official website of State Statistics Bureau). The total population of the elderly is large and the proportion is high. With the development of society and social change, family structure is increasingly getting miniaturization, the traditional family pension model has been challenged. However, China's special conditions of old before getting rich and social security development determines that the government cannot do pension befits well by themselves. What's more, the traditional family pension and institutions pension can not meet our current actual needs. Community home care not only can make the elderly return to the family and the familiar community environment, get family comfort and care at the same time, also they can enjoy the life care, medical rehabilitation, spiritual comfort and other social resources, professional services provided by government, social organizations. The pension model of acquiring more social resources and strength is suitable for the majority of the elderly; in the meanwhile, it is more suitable for China's economic development and social ideas.

\section{The DeVEloping Situation OF CHINESE CoMmUNITY HOME-BASED CARE}

In the 1950s, in order to cope with the trend of "deinstitutionalization", the United Kingdom first proposed community care model and it gradually popularized. Later, in response to the idea of "home-based care for the aged", some countries began to explore community pension model suitable for their national conditions, and made great effect. In the 1980 s, in order to cope with the aging and solve the social pension problem, China, inspired by the international domestic pension trend, began to implement the home care service across the country, and continued to update relevant laws and regulations, policy documents and standard standards, such as Law of the People's Republic of China on the protection of the rights and interests of the elderly promulgated in 1996, which makes legal protection of the rights and interests of the elderly, and was revised again in 2015; it provided a legal basis for the country to develop home care business. "Some suggestion on accelerating the development of pension services" issued in 2013 clearly pointed out that by 2020, a home-based, community-based, and institutional support as well as functional, moderate scale, covering urban and rural pension service system should be built. "The thirteenth five-year plan of civil affairs development" issued in 2016 proposed to speed up the construction of community home care services and improve the pension system to provide convenience for the elderly in urban and rural communities. With the introduction of a series of national policies, all regions responded positively, and they explored a number of new models combined with the local reality, such as community center service operations, property management and operation of the company, and the star of the elderly operating mode; all of them pushed the new development of community home pension model in our country.

However, observing from the actual effect of the operation, the problems of shortage of funds, nonstandard management idle a large number of facilities, low-leveled and unprofessional service and other issues are universal, needs of the elderly cannot meet, supply and demand of pension service contradict. The author believes that the main reasons are that the main body of the community pension service is unclear, resulting in poor cooperation among the organizations; pension service industry lacks specific planning, resulting in slow development of market; the lack of a unified system of related 
operations and service standards, resulting in insufficient efficient supply of services. The development of Chinese community home care is still in an initial stage, and people should make unremitting exploration on it.

\section{RELEVANT INTRODUCTION AND INSPIRATION OF THE INTERNATIONAL CLASSIC HOME-BASED CARE}

Western developed countries entered the aging society earlier, and the aging phenomenon in Europe, the United States, Japan and other countries is serious; its explorations on old-age services are earlier and more comprehensive. Considering China's national conditions and pension status, this section selects the United States, Japan the two typical and very successful home-based pension projects and give them a detailed introduction to draw useful experience and blend them into the construction of Chinese community home care service according to local conditions.

\section{A. The Main Models of Home Care in the United States}

US home care mainly relies on its medical insurance system, and it supports the development of home care by using medical insurance.

Service program: in the 1970s, the PACE model emerged in the United States, and it focused on a home-based care model that combined with short-term and long-term care in a community service system. Its main targets are the people over 55 years or older, which are so frail, sick or unable to move freely and qualified to live in nursing home but still tend to and can live in the community.

Services: based on basic health insurance, the PACE program forms a comprehensive, long-term sustainable care program that provides all medical care services for the elderly. It can be divided into three categories: firstly, medical services, including acute care services, hospitalization, nursing home care; secondly, rehabilitation services, including nutrition counseling, psychology counseling, physical and recreational facilities services, etc.; thirdly, social support services, mainly reflected in the the humanistic transformation of residential facilities, diet and other domestic affairs. The all-around integrated service model from prevention, treatment, care and social support has greatly facilitated elderly patients (it has a professional multidisciplinary nursing team to develop casebased care and follow-up services for the elderly).

Source of funds: PACE project funds mainly are from the monthly relief funds that medical insurance and medical assistance paying to eligible elderly people and other social funds. On account of different payment standards of medical insurance and medical assistance, the project participants that only meet the medical insurance conditions, but do not meet the conditions of medical assistance should make up the difference by themselves. The PAEC Center aggregates funds and manages them uniformly and distribute according to needs, so participants do not need to pay any other medical expenses. The model of revenue and expenditure integration makes the model participants, payers, project providers, and service consumers enjoy cost-effectiveness, saving the total cost.

\section{B. The Main Models of Home-based Care in Japan}

Unlike the United States, because of its cultural tradition differences, Japan emphasizes national independence, which is characterized by the organic integration of home care and long-term care relying on the community.

Service: The Japanese government formally adopted the Nursing Care Insurance Law at the end of 1997, and began to implement nurse insurance law in 2000; based on the "Insurance Law for the Elderly" introduced in 1963 and the "Old People's Insurance Law" established in 1982 , the law integrated the elderly welfare and the elderly medical system well, offering an effective solution to the problems that welfare of the elderly can not meet the elderly patients' care needs after the treatment, so that they can not and do not want to leave the hospital, resulting in the waste of medical resources, unequal resource allocation.

Services: The establishment of a professional service team can be broken down into primary and secondary home caretakers, caregivers, care providers and care support staff. The services providing nursing care, medical care and rehabilitation services can be divided into two categories: one is home care, including household care, home bathing service, living skills recovery training, home care, residential renovation and other service items; the second is specialized care, including nursing care of elderly care and care facilities, medical care of elderly care welfare facility, medical care of nursing care medical facility and other services. Services are diversified, the insured can choose different services according to their needs, and the services are co-supplied by the government and social organizations, of which the latter is the main provider.

Source: The funds required by the system are shared by the government, society and individuals. The insured are responsible for $10 \%$ of the funds, and the remaining $90 \%$ is borne by the insurer (half of the funds are made up of the insurance by all the insured persons of the country; for the rest the central government tax is responsible for $25 \%$, local government finance is responsible for $25 \%$ ).

\section{Enlightment}

Through the detailed introduction of home care services in the United States and Japan, it can be seen that although the two countries have different practices, but they have basically the same direction of development: First, government supervision, the government is responsible for the development of laws and regulations, policy guidance and supervision in the construction of home care services, however, for specific services, they are provided by organization according to market-oriented principle; Second, the government adopts the integration of health care and pension, and the medical insurance system works as a basis for the home pension model to provide funding, in the meanwhile, medical care is regarded as a key project integrated into the community home care service system; besides, the government integrates medical and pension resources to build a practical home care system of high quality; Thirdly, family and society assume joint pension responsibility, emphasizing the responsibility and significance of the family and that 
government should subsidies. Based on the basic concepts above and combined with the problems that emerged in the exploration of Chinese community home-based care, the writer will give some specific recommendations below.

\section{STRATEGIES AND COUNTERMEASURES OF OPTIMIZING CHINA'S COMMUNITY HOME-BASED CARE}

\section{A. Clarifying the Service Body to Play the Role of Non-profit Organizations}

Community home care is a comprehensive public service system, and it needs multi-participation in the construction; single government supply and low efficiency are difficult to meet the diverse needs of the pension. The US government runs indirect guidance on the community home care model, and it promotes the development of community pension services by purchasing service and introducing social forces. At this point, China can effectively learn from the community home care model in the US: government is responsible for planning and management, and social organizations and professional organizations provide specific services to enhance the vitality and professionalism; while the market mechanism has a strong profitability, not suitable for the main body of community pension services. In this way, I think we should give full play to the advantages of non-profit organizations, and guide them to play a full role in the field of community pension services and operate Chinese community home care industry by developing the model of public service.

Nonprofit organizations have public interests, and they are non profit and independent. Nonprofit organizations accept the guidance and arrangements of government and they enter the community home care system as community service projects providers. First, they can relieve the pressure on the government to leave it more energy for its macro management, better implement its policy formulation, legal supervision and other functions; Second, the forms of non-profit organization are flexible, each independent organization is only responsible for a few specific home care services, which improve professionalism, contribute to comprehensive and rich service of high quality as well as better meet the diverse needs of elderly on the home care service both in material and spirit; At the same time, they can be good balances of the market and government mechanism, avoid both low efficiency of government bureaucratic administration and the vicious competition in pursuing sectoral interests in market mechanism in private enterprises, and balance the efficiency and fairness. It can be seen that nonprofit organizations have an advantage over government and private enterprises in providing home care services, and it can be confirmed from the successful experience in the United States and Japan.

Playing the role of non-profit organizations well needs the double efforts of the government and non-profit organizations. First of all, the government should have correct orientation, and they should transfer from the previous provider to designers providing financial support and policy guidance support for non-profit organizations, such as the allocating construction land, giving tax incentives, subsidies, etc.; establish and improve the relevant laws and regulations, give legal status for non-profit organizations to participate in the community home care service, develop a reasonable access to the approval system and control system, helping non organizations provide better service.

Non-profit organizations should strengthen their own construction, train professionals, be equipped with high-tech and humanized facilities, using advanced technology and management methods to provide high-quality services for the elderly; and regulate their own behavior, comply with industry standards and ethics, act strictly according to government regulations system, and consciously accept the the supervision of government and the community to establish a positive image, win the trust of the people and enrich its sources of funding.

\section{B. Practicing the Concept of Medical Integration to Establish Long-term Care System for the Elderly}

It is estimated that by the end of 2050, the population of the elderly in China will reach 200 million, of which the population of disabled, half disabled, dementia, more than 80 years old is about 50 million, and there is a large number of population in need of nursing, which is very urgent. It is necessary to consider from the system, policies and regulations, infrastructure construction and so on to mobilize the main body of the society and establish a complete community home care service system based on medical care and the integration of the basic elder care and nursing projects (two dimensions: horizontal, the cooperation of medical institutions and community pension agencies, the ooperation and resource sharing within and among the community collaboration; vertical: primary, secondary, professional care.)

In China, home-based care is still in the phase of a preliminary attempt for the lack of operating funds, limited medical resources access to the community and families, less projects can be included into the medical insurance and rehabilitation, and the integration of health care and endowment is a broad concept, lacking a set of operable and specific system. Pension, it is a social problem of political nature, and it's urgent to set up old-age insurance systems. Based on China's actual conditions and successful experience in the US and Japan, the writer thinks the long-term old-age care system can be cited as the system foundation of the homebased care system, and the government should develop and constantly improve the relevant laws and regulations, individual regulations, specific rules, etc., formally incorporate the system into the social security system. The funds are shared by the community. Medical care facilities and services are also officially included in the planning system of community home service construction to build an integrated pension service system including prevention, diagnosis and treatment, nursing rehabilitation, hospice care, and daily life care, psychological and cultural care. In the system design, the government should take into account both the efficiency and fairness, and emphasize the social security fairness and redistribution, implement co-ordination, adhere to Pratt \& Whitney principle, bring all the elderly in urban and rural areas into this system, and give policy support to the elderly and low-income groups. Based on the community, playing the core role of the family with the help of government and social forces, making experience in a conditional place to actively 
pilot to explore the sustainable model to point to face can gradually achieve full coverage.

\section{Establishing Professional Personnel Makes Home Care Services Professional}

Both the multidisciplinary service group in the United States and the professional nursing talent teams in Japanese have played an important role in the successful practice in their home care model. However, the population of the staff with pension caregiver professional qualification certificates in China now is only about 50,000 , while correspondingly actual demand is 6 million to 10 million, and the problems of poor professional and technical as well as the great age span are very common; the huge gap in "supply side" elements of health care making the system design may be turned into a bubble no matter how good it is. The root of the problem lies in the whole society's understanding of the attributes of the pension industry. It is necessary to realize that the social pension is not the relief of the government and the employment of the simple family. The pension service industry has great potential and its economic value and technical content are high. It should form correct ideas on the pension service industry in the society and enhance the social recognition of the occupation. First of all, the service personnel training system should be established and improved, and the government should develop talent strategy from the national level to subdivide jobs into on-the-job training and on-the-job training according to the requirements of the specific job segmentation, and cooperate with joint universities and related institutions to set the appropriate theoretical training and professional skills training courses; after staff serving to the posts, the government should establish vocational incentive mechanism and improve wages and benefits appropriately, establish wage growth mechanism and job promotion channel, set the vocational qualification certification system in order to make the home care service professional and enhance the enthusiasm and self-identity of staff.

\section{To Build Intelligent Pension Platform Based on Informatization}

In the practice of community model exploration in our country, one of the big problems is the uneven supply and demand of services which causes that the utilization rate of service items, facilities and products is low, the needs of the elderly are not satisfied, the service satisfaction is low. The direct reason is that the information asymmetry; to solve the problem, the government must establish a scientific and rational needs assessment system as well as supervision and evaluation system, introduce the idea of Internet plus, build hardware facilities and software services management, and improve large data platform.

In the infrastructure construction, the government should do planning first, and the design of hardware should be elderly-oriented and the professional details should be paid attention to in order to meet the support demand of the elderly. In the area of software service management: firstly, the government should build an information database for the elderly to understand the demand category according to their physical condition, living condition and economic capacity, and locate the service level taking demand as its gudlines, so that the government can formulate relevant policies and the communities provide effective services, and establish a comprehensive community home care service network on this basis to make resources in the community be deployed and shared among communities; in the meantime, building medical information exchange platform makes the effective docking of e-health files of the elderly and cooperation Medical information, achieving timely and accurate service; Secondly, the government should build intelligent monitoring and service terminal system to understand the real-time dynamic of the elderly and provide emergency warning and emergency calls, home care, nursing appointment, health and psychological counseling and other services; meanwhile, open community service project plate and the service personnel information platform including the specialist, doctors, community workers, volunteers and other service workers should be constructed to achieve information symmetry, give the elderly and their families the rights to choose and to know; finally, establishing assessment and supervision systems on the basis of it to collecte and summarize policy implementation, service availability, satisfication of the elderly so as to amend or reject bad service projects timely and eliminate inefficient services.

\section{CONCLUSION}

Pension, as a social problem, needs to integrate the power of the whole society to jointly build a community home care system of the sustainable development. As a leader, the government should combine with China's national conditions, learn from foreign advanced concepts, do planning first, design specific home-based care system, formulate relevant laws and regulations to regulate the operation, and advocate the correct ways of social pension. And on this basis the government should continue to explore the specific rules of practice, so as to promote the development of China's pension career and build a harmonious society.

\section{REFERENCES}

[1] Jia Shengge. A glimpse of the American community Endowment. Xinmin Evening News Digital News, 2011-10-18.

[2] Li Hao. The Wonder of Japanese Nursing Insurance [J]. New sight, 2011, (5).

[3] Wang Qiumei, Tian Xinping, Shen Ti. A comprehensive model of services for the elderly in the United States [J]. Chinese Journal of Gerontology, 2010,30 (4): 567-569.

[4] Yuan Xiaohang. Research on the Innovation of the Mode of Homebased care in "combination of medical treatment and endowment" [D]. Hangzhou: Zhejiang University, 2013: 5-6.

[5] Peng Yanfang A review of domestic urban home care research [J]. Social work (theoretical discussion), 2010, (3) volume two.

[6] Qifeng, Xue Zhongyi. The development and enlightenment of home care service in Japan [J]. Northeast Asia Forum, 2010, (04)

[7] Ikko Ikigase. Exploration of protection and welfare science [M]. Beijing: Chinese social publishing company, 2009.22-23.

[8] Chen Yali. The exploration and thinking of the old - age model of the community - Taking Guangzhou as an example [J]. Social Sciences, 2011, (6) : $51-54$.

[9] Zhao Ming, Sang Huayue. A New Probe into the Pattern of Home-based care in the Urban Community in the Background of Aging — Based on the Investigation of Some Mature Communities in Hangzhou [J]. 
Journal of Hubei University of Economics (Humanities and Social Sciences), 2014, (10): 79. 